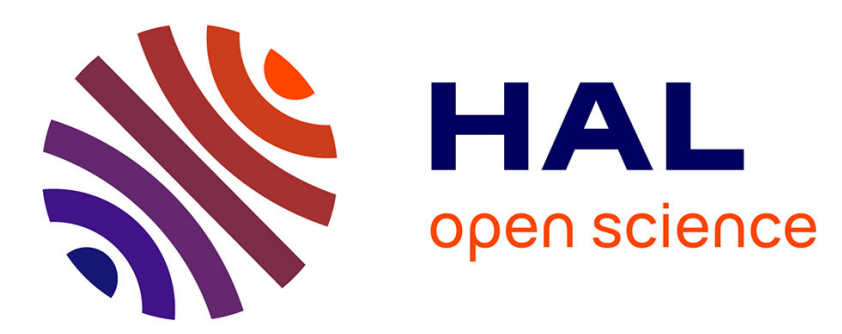

\title{
Biased Probability Judgment: Evidence of Incidence and Relationship to Economic Outcomes From a Representative Sample
}

Thomas Dohmen, Armin Falk, David Huffman, Felix Marklein, Uwe Sunde

\section{- To cite this version:}

Thomas Dohmen, Armin Falk, David Huffman, Felix Marklein, Uwe Sunde. Biased Probability Judgment: Evidence of Incidence and Relationship to Economic Outcomes From a Representative Sample. Journal of Economic Behavior and Organization, 2009, 72 (3), pp.903. 10.1016/j.jebo.2009.07.014 . hal-00723191

\section{HAL Id: hal-00723191 \\ https://hal.science/hal-00723191}

Submitted on 8 Aug 2012

HAL is a multi-disciplinary open access archive for the deposit and dissemination of scientific research documents, whether they are published or not. The documents may come from teaching and research institutions in France or abroad, or from public or private research centers.
L'archive ouverte pluridisciplinaire HAL, est destinée au dépôt et à la diffusion de documents scientifiques de niveau recherche, publiés ou non, émanant des établissements d'enseignement et de recherche français ou étrangers, des laboratoires publics ou privés. 


\section{Accepted Manuscript}

Title: Biased Probability Judgment: Evidence of Incidence and Relationship to Economic Outcomes From a Representative Sample

Authors: Thomas Dohmen, Armin Falk, David Huffman, Felix Marklein, Uwe Sunde

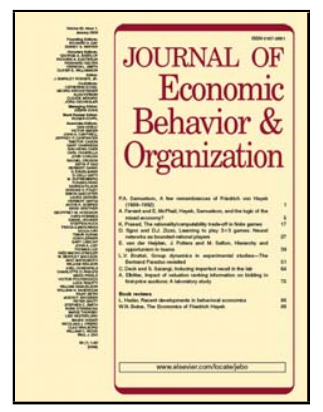

PII: S0167-2681(09)00195-4

DOI: doi:10.1016/j.jebo.2009.07.014

Reference: JEBO 2432

To appear in: Journal of Economic Behavior \& Organization

Received date: $\quad 10-12-2008$

Revised date: $\quad 30-7-2009$

Accepted date: $\quad 31-7-2009$

Please cite this article as: Dohmen, T., Falk, A., Huffman, D., Marklein, F., Sunde, U., Biased Probability Judgment: Evidence of Incidence and Relationship to Economic Outcomes From a Representative Sample, Journal of Economic Behavior and Organization (2008), doi:10.1016/j.jebo.2009.07.014

This is a PDF file of an unedited manuscript that has been accepted for publication. As a service to our customers we are providing this early version of the manuscript. The manuscript will undergo copyediting, typesetting, and review of the resulting proof before it is published in its final form. Please note that during the production process errors may be discovered which could affect the content, and all legal disclaimers that apply to the journal pertain. 


\title{
Biased Probability Judgment: Evidence of Incidence and Relationship to Economic Outcomes From a Representative Sample*
}

\author{
Thomas Dohmen $\ddagger$ \\ ROA, Maastricht University, and IZA \\ Armin Falk \\ University of Bonn, IZA, and CEPR \\ David Huffman \\ Swarthmore College and IZA \\ Felix Marklein \\ $B M F$, Berlin, and IZA \\ Uwe Sunde \\ University of St. Gallen, IZA, and CEPR
}

\begin{abstract}
Many economic decisions involve a substantial amount of uncertainty, and therefore crucially depend on how individuals process probabilistic information. In this paper, we investigate the capability for probability judgment in a representative sample of the German population. Our results show that almost a third of the respondents exhibits systematically biased perceptions of probability. The findings also indicate that the observed biases are related to individual economic outcomes, which suggests potential policy relevance of our findings.
\end{abstract}

JEL classification: C90, D00, D10, D80, D81, H00

Keywords: Bounded Rationality, Probability Judgment, Gambler's Fallacy, Hot Hand Fallacy, Representative Design, Long-Term Unemployment, Financial Decision Making.

*The authors thank Johannes Abeler, Steffen Altmann, Bart Golsteyn, Alexander Hagen, Annemarie Nelen and Matthias Wibral, seminar audiences at the VfS Jahrestagung 2008, Graz, and two anonymous referees for helpful comments and discussions. We thank the German Science Foundation DFG (through GRK 629 and SFB/TR 15), IZA Bonn and the Bonn Graduate School of Economics, as well as the European Research Council (Starting Grants) for financial support.

$¥$ Corresponding author: ROA, Maastricht University, Tongersestraat 53, 6211LM Maastricht, Phone: +31 43 3883647, Fax: +31 433884914 , Email: t.dohmen@maastrichtuniversity.nl 


\section{Introduction}

Economic decisions often involve a significant amount of uncertainty. A thorough understanding of economic decision making is therefore only possible by investigating how people actually form probability judgments. Economic theory typically assumes that decisions will be consistent with the basic laws of probability theory. In contrast, a large number of experimental studies has shown that humans frequently make mistakes in processing probabilistic information. ${ }^{1}$ Despite the extensive experimental evidence, three important questions have received little attention so far: Can the cognitive biases we observe in laboratory subject pools also be documented in the general population? To what extent are individual characteristics, such as measures of cognitive ability, related to biased probability judgment? And, finally, are biases in probability judgment related to individual economic outcomes?

In this paper we address these questions about individual decision making under uncertainty by directly measuring the capability for probability judgment in a representative sample of more than one thousand individuals drawn randomly from the adult population in Germany. This procedure allows us to explore the pervasiveness of cognitive biases in the general population. In a second step, we study the determinants of biased probability judgment, with a particular focus on respondents' education levels and cognitive abilities. Finally, we assess the relationship between biased probability judgment and individual economic outcomes.

We elicit respondents' abilities in probabilistic reasoning via a survey question that addresses two fundamental biases in probability judgment. The first bias, which is often referred to as the "gambler's fallacy", induces individuals to view random processes as having self-correcting properties, which is in direct contradiction to the principle of independence between random outcomes. The gambler's fallacy has been widely discussed in the literature, starting with a famous essay by Laplace (1820). In the paper "Concerning Illusions in the Estimation of Probabilities", Laplace states:

\footnotetext{
${ }^{1}$ See for example Tversky and Kahneman (1971), Grether (1980), Charness and Levin (2005). A comprehensive overview is given by Conlisk (1996).
} 
When a number in the lottery of France has not been drawn for a long time, the crowd is eager to cover it with stakes. They judge since the number has not been drawn for a long time that it ought at the next drawing to be drawn in preference to others. So common an error appears to me to rest upon an illusion by which one is carried back involuntarily to the origin of events. It is, for example, very improbable that at the play of heads and tails one will throw heads ten times in succession. This improbability which strikes us indeed when it has happened nine times, leads us to believe that at the tenth throw tails will be thrown. (p. 161ff)

We designed our probability task such that respondents were confronted with the following series of eight tosses of a fair coin: tails - tails - tails - heads - tails - heads - heads - heads. Respondents then had to indicate the probability with which tails occurs in the next toss of the coin. The correct answer is $50 \%$, as the coin tosses are independent of each other. Since the sequence ends with a streak of three heads, the gambler's fallacy would lead respondents to predict that tails comes up with a probability of more than $50 \%$. The opposite bias, the so-called "hot hand fallacy", implies the belief that the streak of heads at the end of the sequence is likely to be continued. Thus, the hot hand fallacy would lead respondents to indicate a probability of less than $50 \%{ }^{2}$ Since the terms gambler's fallacy and hot hand fallacy are well established in the literature, and for the sake of clarity, we will continue to use these terms as synonyms for the two fundamental biases in probability judgment under investigation in the remainder of the paper.

The probability task was administered to a sample of more than 1,000 individuals, drawn to be representative of the German population. Results show that $60.4 \%$ of the respondents give the correct answer. Thus, a majority of the respondents is aware of the independence between random outcomes. Among the incorrect answers, the gambler's fallacy is the most frequent bias: $21.1 \%$ of the respondents overestimate the probability for tails. In contrast, $8.8 \%$ answer in line with the hot hand fallacy, as they underestimate this probability. The answer "I don't know" is given by $9.6 \%$ of the sample. Our findings have two important implications: first, a substantial share of the population seems to lack basic knowledge about stochastic processes and therefore exhibits biased probability judgment. Second, the biases we observe are systematic, as deviations from the normative solution are not distributed randomly. Rather, among people who make a mistake, the gambler's fallacy is the predominant bias.

\footnotetext{
${ }^{2}$ The term hot hand derives from basketball, where players who make a shot are often believed to be more likely to hit the next shot, in contrast to players who miss a shot (see for example Gilovich et al., 1985).
} 
In order to address the determinants of biased probability judgment, the survey elicited a number of background variables such as education, age, and gender. Our empirical analysis shows that more educated people are much more likely to answer correctly. Moreover, we find a gender effect, with women being less likely to give the correct answer. A special advantage of the data set is that it includes two cognitive performance tasks that distinguish between two components of intellectual ability (Lang et al., 2007). One test assesses perceptual speed and is designed to measure the mechanics of cognition, i.e. the hard-wired biology-related capacities of information processing (also often referred to as fluid intelligence). The other test measures word fluency which proxies for educational and experience-related competencies, i.e. knowledge (also referred to as crystallized intelligence). ${ }^{3}$ These measures relate to respondents' answers in plausible ways: whereas the measure for knowledge is positively correlated with answers to the probability question, the measure for perceptual speed has no explanatory power. ${ }^{4}$ This finding is consistent with the view that a correct perception of the independence between random outcomes relies mainly on acquired knowledge, not on respondents' mechanical cognitive functions.

As uncertainty is a crucial factor in many economic decisions, one would expect that biased probability judgment is related to individual economic outcomes. The gambler's fallacy and the hot hand fallacy are likely to affect economic decision making in domains where people base their decisions on a sequence of realizations of a random process. In particular, these two biases should matter in situations where a streak of similar outcomes has occurred prior to the decision and imply opposite predictions for economic outcomes. Our data contain information about behavior in two domains where the specific forms of judgment biases studied in this paper are potentially relevant: job search decisions by an unemployed person and consumption decisions by a cash-constrained consumer.

In the empirical analysis, we find that being prone to the gambler's fallacy is not associated with a significantly higher probability of being long-term unemployed, while being prone to the hot hand fallacy implies a significantly higher probability of long-term unemployment. ${ }^{5}$ The results

\footnotetext{
${ }^{3}$ See also the seminal contribution by Cattell (1963).

${ }^{4}$ Based on data from a web-based experiment among a sample of university students, Oechssler et al. (2009) report that higher cognitive ability is associated with lower incidences of biased judgment.

${ }^{5}$ Probit estimates indicate that exhibiting the hot hand fallacy is associated with a $6.1 \%$-point increase in the probability of being long-term unemployed, controlling for background characteristics such as age, gender, years of schooling, and household wealth.
} 
also suggest that financial behavior is related to people's ability to form probability judgments, with people who exhibit the gambler's fallacy being significantly more likely to overdraw their bank account. ${ }^{6}$ These distinct effects are noteworthy, as they point at potentially very different implications for distinct biases in probability judgment. Of course, one has to be very careful in interpreting these empirical findings, as job search decisions and financial decisions are highly complex and likely to be influenced by many other factors, including institutions, preferences and abilities other than probability judgment. Nevertheless, our findings allow us to speculate about a direct link between people's perception of probabilities and their actual economic decisions. In particular, the finding that the hot hand fallacy appears to be important in job search decisions, whereas the gambler's fallacy appears relevant for financial decisions suggests that it is not biased probability judgment per se that determines economic outcomes, but rather the specific form of a person's bias within the particular context in which economic decisions are made.

Our paper contributes to the recent literature on cognitive biases and the gambler's fallacy by presenting results from a representative sample, which allows us to draw conclusions about cognitive biases in the general population. ${ }^{7}$ Rabin (2002) has shown from a theoretical perspective that the gambler's fallacy can be interpreted as people's tendency to exaggerate the degree to which a small sample reflects the properties of the underlying data generating process. A number of empirical studies has used field data to investigate probability judgment biases. Clotfelter and Cook (1993) demonstrate that lottery players act in line with the gambler's fallacy: evidence from the Maryland state lottery shows that in the days after a winning number has been drawn, betting on this particular number drops significantly. Terrell (1994) investigates field data from horse races and finds that betting behavior is consistent with the gambler's fallacy. Croson and Sundali (2005) investigate the betting behavior of roulette players in a casino in Reno, Nevada. They find that a long streak of the same outcome leads players to bet disproportionately on the opposite outcome. For example, a streak of 5 times red in a row leads to significantly more bets on black. Note that all these studies rely on aggregate data, as for instance the total number of bets placed on a particular number. In contrast, an important feature of our analysis is that we elicit individual data

\footnotetext{
${ }^{6}$ Being prone to the gambler's fallacy increases a person's probability for having an overdrawn bank account by $8.8 \%$-points, while the share of people with an overdrawn bank account in the total sample is $16.6 \%$.

${ }^{7}$ For instance, Hogarth (2005) argues in favor of a more representative design of empirical research in economics and a more careful assessment of the circumstances under which evidence from experiments can be generalized to the population at large.
} 
about respondents' perception of probabilities. Moreover, our data set contains information about respondents' educational background, cognitive ability, and individual economic outcomes. Our findings therefore complement recent evidence on financial literacy (see, e.g., Lusardi and Mitchell, 2007, 2008) in the population by shedding new light on how individuals judge probabilities.

Several studies have argued that the effectiveness of policy measures could be improved by taking into account that a substantial part of the population exhibits non-standard decision making patterns (Bernheim and Rangel, 2007; Bertrand et al., 2004). As a first step in this direction, the methodology employed in this paper can inform policy makers about the actual prevalence of probability judgment biases and about the way in which these biases affect economic outcomes. From an applied perspective, our findings have straightforward implications for the design of policy measures on the labor market and in the domain of household debt counseling. Our results suggest that better education of boundedly-rational agents might help 'de-bias' them, and therefore help them to make better decisions, without limiting the freedom of agents who decide optimally in the first place (Camerer et al., 2003; Thaler and Sunstein, 2003).

The remainder of the paper is structured as follows: Section 2 contains a description of the data. Section 3 presents evidence on the pervasiveness of cognitive biases in the population and addresses the determinants of these biases. The link between biased probability judgment and economic outcomes is explored in Section 4, and Section 5 concludes.

\section{Data}

The data set under investigation consists of 1,012 observations and is a representative sample of the population living in Germany aged 16 years and older. The data were collected by the professional interview group TNS Infratest in June and July 2005. Households were contacted by interviewers according to the Random Route Method (see Fowler, 2002) and one person per household was surveyed. All interviewers used the Computer Assisted Personal Interview (CAPI) procedure, administering questions and collecting answers with the help of a notebook computer. To elicit respondents' abilities in making probability judgments, we used the following question (translated from German): ${ }^{8}$

\footnotetext{
${ }^{8}$ The exact wording was: "Nehmen Sie an, Sie werfen eine Münze, die gleichmäßig auf die eine oder die andere Seite fällt. Nach acht Würfen beobachten Sie folgendes Ergebnis: Zahl - Zahl - Zahl - Kopf - Zahl - Kopf - Kopf Kopf. Wie hoch ist die Wahrscheinlichkeit, ausgedrückt in Prozent, dass der nächste Wurf 'Zahl' ist?".
} 
Imagine you are tossing a fair coin. After eight tosses you observe the following result: tails - tails - tails - heads - tails - heads - heads - heads. What is the probability, in percent, that the next toss is "tails"?

We chose the sequence of outcomes such that the overall occurrence of tails in the sample is indeed $50 \%$ (4 out of 8), to avoid raising doubts among the respondents about the coin being fair. Respondents had to answer with a number between $0 \%$ and 100\%. Alternatively, they had the possibility to answer "I don't know". The correct answer is $50 \%$, as the coin is fair and the tosses are independent of each other.

In order to address the determinants of biased probability judgment, the data contain a number of socioeconomic background variables such as education, age, gender, income, and wealth. A novel feature of the survey is that it elicited measures of respondents' cognitive abilities. The design of these measures is based on the two-component theory of cognitive ability, originating from research in developmental psychology (Lang et al., 2005). According to this theory, cognitive ability can be broadly divided into cognitive mechanics and cognitive pragmatics (Baltes et al., 2006; Lindenberger and Baltes, 1997). The mechanics of cognition (fluid intelligence) reflect fundamental organizational properties of the central nervous system (Singer, 1995). In contrast, the cognitive pragmatics (crystallized intelligence) reflect the knowledge-based domain of cognitive ability. Examples of the mechanics of cognition include the speed, the accuracy, and the coordination of cognitive processing operations. Examples of pragmatics include reading and writing skills, educational qualifications, and professional skills.

Respondents' performances in the domain of cognitive mechanics was assessed via a symbol-digit test that has been designed to measure perceptual speed. For this test, respondents had to match the correct digit to symbols on the computer screen. They had to match as many symbol-digit pairs as possible within a time frame of 90 seconds. The CAPI method allows for a direct measurement of performance, registering decisions through software that was running in the background. In the area of cognitive pragmatics, a word fluency test was used to elicit a measure of respondents' general knowledge. The test asked participants to name as many distinct animals as possible in 90 seconds. Lang et al. (2007) and Lang et al. (2005) describe the design of these tests in more detail and examine the validity, internal consistency and retest-reliability of the measures.

Regarding the impact of biased probability judgment on economic behavior, our research question leads us to focus on two specific domains: respondents' employment status and respondents' 
financial situations. With respect to employment status, the data contain information on whether respondents are registered as unemployed. Moreover, respondents have to indicate whether they are long-term unemployed, i.e., unemployed for 12 months and longer. To address respondents' financial situations, they are asked about the number of days (per year) their bank account is overdrawn, and whether their account is currently overdrawn at the time of the interview.

Sample statistics are shown in Table 1. About $53.7 \%$ of the sample are female, average age is 47.6 years, and respondents have on average 10.3 years of schooling. ${ }^{9}$ The measures for cognitive ability have a mean value of 28.3 (symbol-digit test) and 22.9 (word fluency test). For the empirical analysis, both cognitive ability measures are standardized to have variance one and mean zero. Histograms of the two standardized measures are presented in Figure 1. Note that the shape of both distributions resembles a normal distribution. With regard to the economic outcome variables, $11.4 \%$ of the respondents are unemployed, and $16.6 \%$ indicate that their bank account is overdrawn at the time of the interview.

\section{Pervasiveness and Determinants of Biased Probability Judgment}

In this section we document the pervasiveness of cognitive biases in a representative sample of the German population. We then proceed to address the determinants of biased probability judgment. Responses to the probability question are shown in the histogram in Figure 2(a). We find that $60.4 \%$ of the survey participants gave the correct answer of $50 \%$. Thus, a majority of the respondents knows that the toss of a coin does not depend on outcomes of previous tosses. However, $39.6 \%$ seem to lack a basic understanding of probability theory. The answer "I don't know" is given by $9.6 \%$ of the respondents. As can be seen from the histogram, the remaining incorrect answers are spread out over the full range of the answer space, from $1 \%$ to $100 \%$. The average estimate for tails to come up in the next coin toss is a probability of $54.2 \%$. Recall that, as the sequence in our setting ends with a streak of three heads, the gambler's fallacy leads respondents to an estimate of more than 50\%. In contrast, the hot hand fallacy implies an estimate of less than $50 \%$. We find that the gambler's fallacy is exhibited by $21.1 \%$ of the respondents, whereas $8.8 \%$ of the respondents are prone to the hot hand fallacy. Figures 2(b) and 2(c) display histograms of the responses of

\footnotetext{
${ }^{9}$ There are two types of high school in Germany, vocational and university-track. Individuals opting for the vocational track leave school after 9 or 10 years and then typically go on to do an apprenticeship or vocational training. Individuals in the university-track complete an exam, the Abitur, that qualifies an individual to attend university after 12-13 years (depending on the state).
} 
individuals who exhibit the gambler's fallacy and the hot hand fallacy, respectively. The average estimate for tails to come up in the next coin toss is a probability of $79.2 \%$ for individuals prone to the gambler's fallacy, and $22.9 \%$ for individuals prone to the hot hand fallacy.

The fact that the gambler's fallacy is by far more pervasive than the hot hand fallacy indicates that respondents display systematic biases. This relates our results to an important debate in economics and in cognitive psychology (see Conlisk, 1996; Stanovich and West, 2000). According to one side of this debate, observing non-normative answers does not prove that people are boundedly rational. Theoretically, mistakes could be observed even if respondents were fully rational, e.g., due to lack of concentration or due to lack of motivation. However, one would expect such mistakes to be random noise, without a systematic pattern. If the mistakes in our sample were indeed random noise, the share of people who exhibit the gambler's fallacy and the share of people who exhibit the hot hand fallacy should be of approximately equal size. This is clearly not the case, as the gambler's fallacy is more than twice as frequent as the hot hand fallacy. Moreover, a Shapiro-Wilkinson Test rejects the null hypothesis of a Gaussian distribution of the deviations from the normatively correct answer at any conventional significance level $(p<0.001)$. Therefore, our findings indicate that the pattern of non-normative answers is systematic.

An explanation for the fact that the gambler's fallacy is the dominant bias in our setting is suggested by the work of Ayton and Fischer (2004). In their study, subjects were presented with sequences of binary outcomes that had either a high rate of alternations, or a high rate of streaks. Subjects then had to guess whether a given sequence was derived from human performance (e.g., hits and misses of a professional basketball player during a game), or from an inanimate chance process (e.g., heads and tails in the successive tosses of a fair coin). Their study demonstrates that subjects were more likely to attribute sequences with many streaks to human skilled performance. In contrast, sequences with high rates of alternation were attributed to inanimate chance processes. Our results are complementary to these findings, as they show that people who make predictions regarding the outcome of an inanimate chance process tend to overestimate the occurrence of alternations, whereas the belief in streaks is relatively infrequent.

Regarding the determinants of biased probability judgment, several basic insights already emerge from the descriptive statistics. Table 2 provides a look at participants' answers, stratified by education, age, and gender. With respect to high school education, we see that people with more than 10 years of schooling have a relatively high propensity to answer correctly $(72.6 \%$ vs. $54.5 \%$ of 
people with 10 years of schooling or less). Moreover, people with more than 10 years of schooling are very unlikely to either exhibit the hot hand fallacy $(4.6 \%)$ or to answer "I don't know" (4.3\%). Still, they frequently exhibit the gambler's fallacy: $18.5 \%$ of them estimate the probability of tails in the next toss to be higher than $50 \%$. This finding suggests that the gambler's fallacy is prevalent even among highly educated individuals.

Looking at the control variables, we find that gender is an important factor: $65.6 \%$ of men give the correct answer, whereas only $56.0 \%$ of women do so. In particular, women are much more likely to answer "I don't know". Younger people (below 50 years of age) are more likely to give the correct answer, but they are also more prone to the gambler's fallacy. Older people are much more likely to answer "I don't know" (16.2\% vs. $4.5 \%)$.

In the following regression analysis we test whether these determinants are statistically significant and robust to controlling for background characteristics. Table 3 presents probit estimates with the dependent variable being equal to 1 if a respondent gives the correct answer of $50 \% .{ }^{10}$ It turns out that the effect of schooling is large and significant: an additional year of schooling is related to an increase in the probability of giving the correct answer of about 4.5 percentage points $(p<0.01)$, controlling for cognitive ability. As the baseline of correct answers in the total sample is $60.4 \%$, this effect is quite sizeable. For the cognitive ability measures, we see that the coefficient for the word fluency measure is large and significant, whereas the coefficient for the perceptual speed measure is small and insignificant. These results suggest that the cognitive pragmatics (general knowledge) have a decisive impact on giving the correct answer, whereas mechanical cognitive ability (perceptual speed, quick comprehension) is not relevant to answering the question at hand. Given that the task does not involve computational skills but is rather testing knowledge that is part of general education, this is a plausible finding. Regarding the control variables, we find a significant gender effect that persists even if we include age, cognitive ability and years of schooling in the regression. According to the estimates, the probability of giving the correct answer is almost 10 percentage points lower for women $(p<0.01){ }^{11}$

\footnotetext{
${ }^{10}$ For simplicity, answering "I don't know" is categorized as a wrong answer in these regressions. If we exclude these observations from the analysis (i.e., categorize them as missing), the results are very similar. The coefficients for gender and years of schooling remain highly significant, only the word fluency measure turns out to be insignificant.

${ }^{11}$ A similar gender effect has been shown by Charness and Levin (2005), who conducted a laboratory experiment to test under which circumstances individual behavior in a probabilistic decision making task is consistent with standard economic theory. Our data allows us to show in a representative sample that the gender effect persists when we control for background characteristics.
} 
To address the interplay between the nature of participants' cognitive biases and their background characteristics in more detail, we estimate multinomial logit and multinomial probit models (Table 4). These regression methods allow us to determine whether the differences between the separate answer categories are statistically significant. The dependent variable indicates in which of the four categories a respondent's answer is located: either it is correct, or it is consistent with either the gambler's fallacy or the hot hand fallacy, or the respondent answered "I don't know". In the estimations, the reference group consists of those respondents who answered the probability question correctly. This allows us to analyze which factors determine whether a respondent exhibits a particular bias. The estimates confirm our earlier descriptive analysis. For instance, the effect of years of schooling is highly significant: schooling reduces the probability of making a mistake. This finding holds for each of the three possible mistakes, be it the hot hand fallacy, the gambler's fallacy, or the answer "I don't know". Remarkably, the effect of schooling is quite asymmetric: Whereas more schooling protects people from committing the hot hand fallacy (coefficient $-0.293, p<0.01$ when controlling for word fluency in the multinomial logit estimations; coefficient $-0.294, p<0.01$ when controlling for perceptual speed in the multinomial logit estimations), its impact on averting the gambler's fallacy is considerably weaker (coefficients of $-0.122, p=0.02$ and $-0.144, p<0.01$, respectively). This is in line with the descriptive evidence which showed that the gambler's fallacy is quite common among highly educated individuals, whereas the hot hand fallacy is mostly confined to respondents with 10 years of schooling or less. With regard to the control variables, we find that women and older people are significantly more likely to answer "I don't know".

Taken together, our findings regarding the determinants of biased probability judgment all point in the same direction: more schooling increases the likelihood that a respondent gives the correct answer in the probability task. From a policy perspective, it is important to stress that schooling has an effect on probability judgment beyond the impact that works through cognitive abilities. A competing hypothesis would be that the only determinant of probability judgment is cognitive ability, which also related to the amount of schooling a given person obtains. To avoid this confound, we controlled for cognitive ability in all regressions by including measures of respondents' word fluency and perceptual speeds. As the coefficient on years of schooling remains highly significant, the estimates suggest that schooling directly affects people's capability for probability judgment. 


\section{Economic Outcomes and Biased Probability Judgment}

Uncertainty is a crucial factor in many economic decisions. One would therefore expect that biased probability judgment can have a detrimental effect on individual economic outcomes. We investigate two domains in which decisions are of a nature that closely resembles the structure of our probability judgment task: job search decisions by an unemployed person and consumption decisions by a cash-constrained consumer. In the following, we first develop predictions of how the gambler's fallacy and the hot hand fallacy might affect decision making in these domains. In a second step we investigate the hypotheses in our data set.

\subsection{Behavioral Predictions}

The biases that are the focus of this paper are likely to affect economic decision making in domains where agents base their decisions on a sequence of realizations of a random process. A straightforward example of such an environment can be found in the domain of job search. As a thought experiment, assume that a person is looking for a job and sends out a number of ap-

plications. The relevant sequence of random outcomes consists then of the reactions that the job seeker receives to his applications: they can be either negative (a rejection) or positive (a job offer). After observing the realization of a sequence of outcomes, the job seeker has to decide whether to continue his search for a job or not.

Of course, many factors can play a role in the job finding process. For instance, the institutional environment, the particular skills of a job-seeker, as well as his previous work experience might have a large influence on success in the labor market. Still, our approach allows us to speculate about an additional influence that might play a role on top of these factors: the impact of a job-seeker's perception of probabilities on actual job search behavior. Given the nature of the cognitive biases we investigate, we are interested mainly in situations where a streak of similar outcomes has occurred prior to the decision. Consider the case in which a job seeker has received a streak of rejections, and suppose that, as is standard in search models, search outcomes are independent from each other. The probability of generating a job offer is only related to search intensity, a choice variable of the searcher. Then, the two probability judgment biases, gambler's fallacy and hot hand fallacy, would imply different predictions: a person who is prone to the gambler's fallacy should believe that the streak of rejections is going to end, which implies that a job offer has now become more likely. As a consequence, the unemployed will be encouraged to continue his search for a job. In contrast, a 
person who is prone to the hot hand fallacy is going to believe that the streak of rejections is likely to continue. Given this belief, the worker will become discouraged and may give up his search for a job altogether. One would therefore predict that job-seekers who are prone to the gambler's fallacy face a high probability of leaving unemployment. In contrast, the hot hand fallacy can lead to prolonged unemployment by biasing the job-seeker's beliefs about his job finding probability such that they become too pessimistic. ${ }^{12}$ Note that, due to the need for a streak of rejections to occur, our prediction is unlikely to affect persons who just became unemployed a short while ago. Rather, we would expect the detrimental effect of the hot hand fallacy to play a role for job seekers who have been unemployed for a long time. ${ }^{13}$

Another domain where biased probability judgment might have a substantial effect on economic behavior is in the domain of consumption decisions. Assume that a cash-constrained consumer has to decide whether to make a large purchase that exceeds the amount of funds that is currently available in his bank account. Thus, in order to make the purchase, the consumer would have to overdraw his account. In this context, the sequence of random outcomes on which the decision is based can be thought of as unexpected idiosyncratic income shocks that are either positive (e.g., finding a bank note on the sidewalk, winning money in a game of poker with friends) or negative (e.g., receiving a speeding ticket, having a bill to pay that is higher than anticipated). The consumption decision will then depend on the belief whether it is likely that a positive income shock occurs in the near future. If this probability is high, it is optimal to overdraw the bank account for the short period until the positive income shock is realized. If, instead, this probability is low, it is optimal to postpone the purchase until it can be made without overdrawing the account.

\footnotetext{
${ }^{12}$ In the opposite case (in which a streak of job offers has occurred) the theoretical predictions are less clear. Here, it is very likely that both a gambler's fallacy type and a hot hand fallacy type are going to accept one of the job offers and therefore stop searching for a job.

${ }^{13}$ The assumption of a stationary job finding probability, with job offers arriving at a fixed Poisson rate - and therefore the independence of subsequent realizations of job search outcomes - is standard in the search literature. Exceptions are papers considering inherently non-stationary subjective job finding probabilities in an environment in which there is employer stigma, or in which the unemployed have imperfect information about their stationary job finding probability and update their subjective beliefs about this probability. In this context, the unemployed's personal job search history (i.e., past realizations) matters and may lead to a discouraged worker effect, see Falk et al. (2006a, 2006b). These cases would leave the hypotheses arising from biased probability judgment unaffected. For instance, even in a model with learning about the job finding probability, one would predict that a hot hand fallacy type reduces search intensity faster than people without bias in probability judgment, or gambler's fallacy types, after a streak of negative search outcomes for a given job finding rate. This is because hot hand fallacy types overvalue the information content of a streak of negative outcomes since they would predict future outcomes to be more likely to be negative than they really are. Thus, although updating might be the channel through which searchers become long-term unemployed, the underlying reason for hot hand fallacy types to become discouraged faster is their biased probability judgment.
} 
Again, we are interested in a situation where the decision maker has experienced a streak of similar outcomes. Consider the case in which a streak of negative income shocks has occurred. The probability judgment biases lead to the following behavioral predictions: if the consumer is prone to the gambler's fallacy, he will have the belief that the streak of negative income shocks is likely to end, such that a positive income shock will realize with a high probability in the near future. Thus, his inclination to overdraw the bank account in order to make the purchase will be high. In contrast, the hot hand fallacy will lead to the opposite prediction: if the consumer believes that the streak of negative income shocks is likely to continue, he will refrain from overdrawing his account and will not make the purchase. ${ }^{14}$ In sum, a person who is prone to the gambler's fallacy is predicted to be more likely to have an overdrawn bank account, as the biased belief that a positive income shock is "due" can lead to persistent household debt. By contrast, a person who is prone to the hot hand fallacy will be less likely to have an overdrawn bank account.

\subsection{Empirical Results}

To test the predictions regarding employment status with our data, we run two sets of regressions. First, we estimate a probit model in which the dependent variable is a dummy equal to one if the respondent is registered as unemployed at the time of the interview. In a second set of regressions, the dependent variable is an indicator for whether the respondent is long-term unemployed, i.e., registered as unemployed for 12 months or more. As explanatory variables, we include dummies for the observed cognitive biases: the gambler's fallacy, the hot hand fallacy, and the answer "I don't know". The reference group consists therefore of those respondents who answered the probability judgment task correctly. Results from regressions with the unemployment dummy as dependent variable are presented in Table 5. In column (1) we control only for age and gender and find that both the hot hand dummy and the gambler's fallacy dummy are positive and weakly significant. Adding controls for education and for wealth renders both coefficients insignificant, see columns (2) and (3).

In light of the hypotheses described before, our analysis next turns to persons who have been looking for a job for an extended period of time. Columns (4) to (6) present results from regres-

\footnotetext{
${ }^{14}$ Predictions in the opposite case (in which a streak of positive income shocks has occurred) are ambiguous: if the consumer is prone to the hot hand fallacy, he will believe that the positive income shocks are going to continue and he will decide to make the large purchase. If the respondent is prone to the gambler's fallacy instead, he will expect that a negative income shock is likely to occur in the near future. Still, if the streak of positive income shocks has led to a large amount of funds available in his account, he might nevertheless make the purchase.
} 
sions where the dependent variable is a dummy equal to one for respondents who are long-term unemployed. The explanatory variables are the same variables as before. Our estimates show that, controlling for age and gender, the hot hand fallacy is positive and significant at the $1 \%$-level. Thus, the results are consistent with the behavioral predictions regarding the effect of the hot hand fallacy on long-term unemployment. If, in addition, we control for respondents' educational background, the coefficient for the hot hand fallacy remains significant at the 5\%-level. Even if we control for education and wealth, the coefficient for the hot hand fallacy dummy remains significant at the $10 \%$-level and the marginal effect indicates that the probability of being long-term unemployed is increased by $6.1 \%$-points. ${ }^{15}$ Given that the baseline of long-term unemployment in the sample is $6.8 \%$, this is a considerable effect. We therefore conclude that our predictions regarding the detrimental effect of the hot hand fallacy are supported in case of long-term unemployed job seekers. Moreover, we find for all specifications that the gambler's fallacy has no significant effect on employment status, which is again in line with our predictions.

Next, we empirically test the predictions regarding consumption decisions of cash-constrained consumers. To this aim, we analyze the interplay of probability judgment biases and the decision to overdraw one's bank account. In a first set of regressions, the dependent variable indicates how many days per year a respondent's bank account is overdrawn. The variable can take on four distinct values, as the set of possible responses consisted of four intervals ( 0 days, 1 to 30,31 to 90 , more than 90 days). As explanatory variables we include again the dummies for whether a person exhibits a bias in probability judgment, with the reference group being those respondents who gave the correct answer to the probability task. Results of ordered probit regressions are presented in columns (1) to (3) of Table 6 . The estimates show that the dummy for whether a respondent is prone to the gambler's fallacy is positive and significant at the $1 \%$-level even when controlling for age, gender, and education. Adding controls for net household income and net household wealth leaves the coefficient virtually unchanged and significant at the $5 \%$-level. This is in line with the behavioral prediction: people who are prone to the gambler's fallacy have a higher number of days per year on which their bank account is overdrawn.

As it might be relatively complicated for respondents to assess the number of days per year

\footnotetext{
${ }^{15}$ We deliberately chose not to control for household income in the unemployment regressions, in order to avoid endogeneity problems.
} 
on which their account is in the negative, the survey also included the straightforward question of whether a person's account was overdrawn at the time of the interview. A look at the raw data reveals large effects: out of the respondents who answer the probability question correctly, $14.3 \%$ have an overdrawn bank account. In contrast, this figure is $24.5 \%$ among the group of people who are prone to the gambler's fallacy. Results of a probit estimation with this simple measure as dependent variable are presented in columns (4) to (6). The estimates are very similar to our earlier findings: in most specifications, the coefficient on the gambler's fallacy dummy is positive and significant at the 1\%-level. The marginal effects indicate that being prone to the gambler's fallacy increases the probability of having an overdrawn bank account by about 8.8\%-points $(p=0.020)$, controlling for age, gender, education, income, and wealth. This is a sizeable effect, as the share of respondents with an overdrawn bank account is $16.6 \%$ in the total sample. Again, these findings are in line with the predictions: the gambler's fallacy has a substantial impact on consumers' decision to overdraw their bank account.

Taken together, our results are consistent with the behavioral hypotheses that were developed in Section 4.1. In particular, we find that the gambler's fallacy affects financial decision making, whereas the hot hand fallacy has an impact on job search decisions. These findings suggest that it is not biased probability judgment per se that affects economic outcomes. Rather, depending on the context in which economic decisions are made, the specific form of a person's probability judgment bias might play a decisive role.

\section{Conclusion}

This paper addressed three closely related research questions. First, it investigated people's ability to make simple probability judgments. For this purpose, we used a specifically designed probability judgment question that was administered to a representative sample of the German adult population. The results showed that more than a third of the respondents was unable to answer the probability question correctly, indicating that a substantial part of the population has difficulties with making simple probability judgments. Among the incorrect answers, by far the most frequent bias was the gambler's fallacy, i.e., the tendency to overestimate the occurrence of alternations in random sequences. Second, we addressed the determinants of biased probability judgment. Our results have shown that education (years of schooling) and a knowledge-based measure of cognitive ability are positively related to performance in the probability judgment task. The third 
part of the paper explored the relation between the observed probability judgment patterns and respondents' behavior in two domains: job search and financial decision making. The hot hand fallacy, i.e., the tendency to overestimate the occurrence of streaks in random sequences, was shown to be significantly related to a higher probability of being long-term unemployed. In contrast, the gambler's fallacy was found to be associated with a higher probability of overdrawing one's bank account.

If our interpretation of the results, namely that biased probability judgment is likely to translate into inferior economic outcomes, is correct, our findings regarding the impact of schooling are of relevance from a policy perspective. Our estimates have shown that schooling has a large and significant impact on reducing people's cognitive biases. The fact that the estimates were positive and significant even when controlling for cognitive ability suggests that the knowledge obtained in school mitigates probability judgment biases in a direct way. Thus, it may be worthwhile to put a stronger focus on teaching simple probabilistic reasoning in the early grades of high school. More generally, an increased dissemination of basic knowledge about random processes might help people to make better decisions in the economic domains of life.

From an applied perspective, our findings have straightforward implications for the design of policy measures, emphasizing the role of debiasing of decision makers. With respect to labor market policy, our results suggest that job centers should offer courses that teach job-seekers about the probabilities that play a role in the application process. Rather than believing that their future search success will be the outcome of a continued streak of unsuccessful applications, jobseekers should understand that their job finding probabilities depend on the overall labor market conditions in a particular occupation or region, and that the outcome of a particular application does not necessarily directly depend on earlier unsuccessful applications elsewhere. Similar policy implications can be derived for the domain of household finances. Here, counselors who give advice to over-indebted households could inform consumers who exhibit the gambler's fallacy that they should avoid overestimating the probability of a positive income shock occurring in the near future.

Of course, the analysis in this paper has limitations. For instance, we were not able to identify the exact channels through which a cognitive bias influences behavior. While some of our results are in line with the gambler's fallacy being a sign of over-optimism (as in the overdrawn bank account measure), this behavior might as well be related to time-inconsistent preferences or other cognitive biases in financial decision making (see, e.g., Laibson, 1997, or Stango and Zinman, 2009). 
A promising direction for future research is the combination of incentivized measures of people's time and risk preferences with measures of biased probability judgment, in order to identify the channels through which biased probability judgment affects economic behavior. 


\section{References}

Ayton, P., Fischer, I., 2004. The hot hand fallacy and the gambler's fallacy: Two faces of subjective randomness? Memory \& Cognition 32, 1369-1378.

Baltes, P. B., Lindenberger, U., Staudinger, U. M., 2006. Life span theory in developmental psychology. In: Damon, W., Lerner, R. M. (Eds.), Handbook of child psychology: Vol. 1. Theoretical models of human development (6th ed.). Wiley, New York, pp. 569-664.

Bernheim, B. D., Rangel, A., 2007. Behavioral public economics: Welfare and policy analysis with non-standard decision-makers. In: Diamond, P., Vartiainen, H. (Eds.), Behavioral Economics and its Applications. Princeton University Press, pp. 7-77.

Bertrand, M., Mullainathan, S., Shafir, E., 2004. A behavioral-economics view of poverty. American Economic Review, Papers and Proceedings 94, 419-423.

Camerer, C., Issacharoff, S., Loewenstein, G., O’Donoghue, T., Rabin, M., 2003. Regulation for conservatives: Behavioral economics and the case for "asymmetric paternalism". University of Pennsylvania Law Review 151, 1211-1254.

Cattell, R. B., 1963. Theory of fluid and crystallized intelligence: A critical experiment. Journal of Educational Psychology 54, 1-22.

Charness, G., Levin, D., 2005. When optimal choices feel wrong: A laboratory study of Bayesian updating, complexity, and affect. American Economic Review 95, 1300-1309.

Clotfelter, C. T., Cook, P. J., 1993. The "gambler's fallacy" in lottery play. Management Science $39,1521-1525$.

Conlisk, J., 1996. Why bounded rationality? Journal of Economic Literature 34, 669-700.

Croson, R., Sundali, J., 2005. The gambler's fallacy and the hot hand: Empirical data from casinos. Journal of Risk and Uncertainty 30, 195-209.

Falk, A., Huffman, D., Sunde, U., 2006a. Do I have what it takes? Equilibrium search with type uncertainty and non-participation. IZA Discussion Paper No. 2531.

Falk, A., Huffman, D., Sunde, U., 2006b. Self-confidence and search. IZA Discussion Paper No. 2525 .

Fowler, F. J., 2002. Survey Research Methods. Sage Publications, London.

Gilovich, T., Vallone, R., Tversky, A., 1985. The hot hand in basketball: On the misperception of random sequences. Cognitive Psychology 17, 295-314. 
Grether, D. M., 1980. Bayes rule as a descriptive model: The representativeness heuristic. Quarterly Journal of Economics 95, 537-557.

Hogarth, R. M., 2005. The challenge of representative design in psychology and economics. Journal of Economic Methodology 12, 253-263.

Laibson, D., 1997. Golden eggs and hyperbolic discounting. The Quarterly Journal of Economics 112, 443-477.

Lang, F. R., Hahne, D., Gymbel, S., Schröpper, S., Lutsch, K., 2005. Erfassung des kognitiven Leistungspotenzials und der "Big Five" mit Computer-Assited-Personal-Interviewing (CAPI): Zur Reliabilität und Validität zweier ultrakurzer Tests und des BFI-S, DIW Research Notes 9/2005, DIW Berlin.

Lang, F. R., Weiss, D., Stocker, A., von Rosenbladt, B., 2007. Assessing cognitive capacities in computer-assited survey research: Two ultra-short tests of intellectual ability in the german socio-economic panel (soep). Schmollers Jahrbuch 127, 183-192.

Laplace, P., 1820. Philosophical Essays on Probabilities. Dover, New York, (translated by F.W. Truscott and F. L. Emory, 1951).

Lindenberger, U., Baltes, P. B., 1997. Intellectual functioning in old and very old age: Crosssectional results from the Berlin Aging Study. Psychology and Aging 12, 410-432.

Lusardi, A., Mitchell, O. S., 2007. Baby boomer retirement security: The roles of planning, financial literacy, and housing wealth. Journal of Monetary Economics 54, 205-224.

Lusardi, A., Mitchell, O. S., 2008. Planning and financial literacy: How do women fare? American Economic Review 98, 413-417.

Oechssler, J., Roider, A., Schmitz, P., 2009. Cognitive abilities and behavioral biases. Journal of Economic Behavior and Organization, forthcoming.

Rabin, M., 2002. Inference by believers in the law of small numbers. Quarterly Journal of Economics $117,775-816$.

Singer, W., 1995. Development and plasticity of cortical processing architectures. Science 270, 758 764 .

Stango, V., Zinman, D., 2009. Exponential growth bias and household finance. Journal of Finance, forthcoming.

Stanovich, K. E., West, R. F., 2000. Individual differences in reasoning: Implications for the rationality debate? Behavioral and Brain Sciences 23, 645-726. 
Terrell, D., 1994. A test of the gambler's fallacy: Evidence from pari-mutuel games. Journal of Risk and Uncertainty 8, 309-317.

Thaler, R. H., Sunstein, C. R., 2003. Libertarian paternalism. The American Economic Review 93, $175-179$.

Tversky, A., Kahneman, D., 1971. Belief in the law of small numbers. Psychological Bulletin 2, $105-110$. 


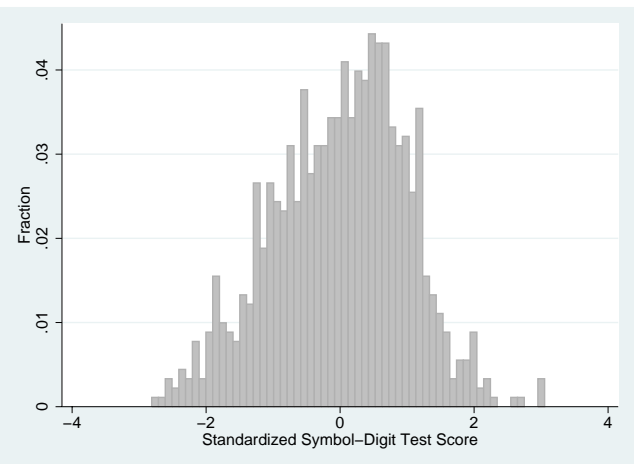

(a) Standardized perceptual speed test, measuring fluid intelligence. Respondents had to match as many digits and symbols as possible in 90 seconds of time.

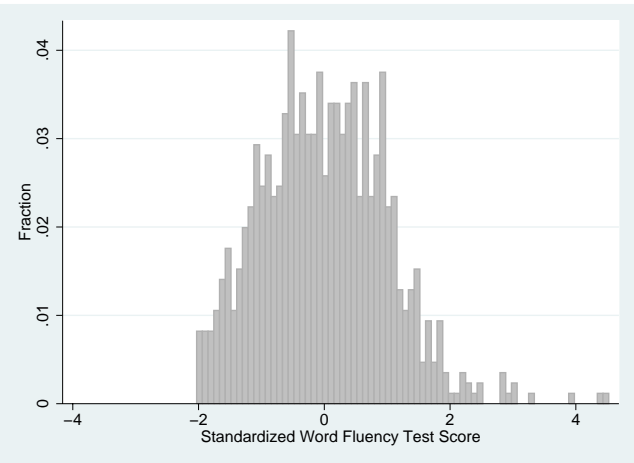

(b) Standardized word fluency test, measuring crystallized intelligence. Respondents had to name as many distinct animals as possible in 90 seconds of time.

Figure 1: Measures of Cognitive Ability.

Table 1: Sample Statistics.

\begin{tabular}{lccc} 
& & & \\
\hline \hline & & & \\
Variable & average & std. dev. & num. obs. \\
& & & \\
\hline & & & \\
1 if female & 0.537 & $(0.499)$ & 1,012 \\
Age & 47.555 & $(18.371)$ & 1,011 \\
Years of schooling & 10.328 & $(1.829)$ & 965 \\
Perceptual speed test (raw data) & 28.309 & $(9.890)$ & 903 \\
Perceptual speed test (standardized) & 0 & $(1)$ & 903 \\
Word fluency test (raw data) & 22.807 & $(10.986)$ & 853 \\
Word fluency test (standardized) & 0 & $(1)$ & 853 \\
Log net household income (per month) & 7.521 & $(0.635)$ & 940 \\
Log net household wealth & 7.177 & $(5.421)$ & 772 \\
1 if unemployed & 0.114 & $(0.318)$ & 1012 \\
1 if long-term unemployed & 0.068 & $(0.252)$ & 1012 \\
Account overdrawn & 1.504 & $(0.885)$ & 943 \\
1 if account overdrawn at time of interview & 0.166 & $(0.372)$ & 1012 \\
& & & \\
\hline \hline
\end{tabular}




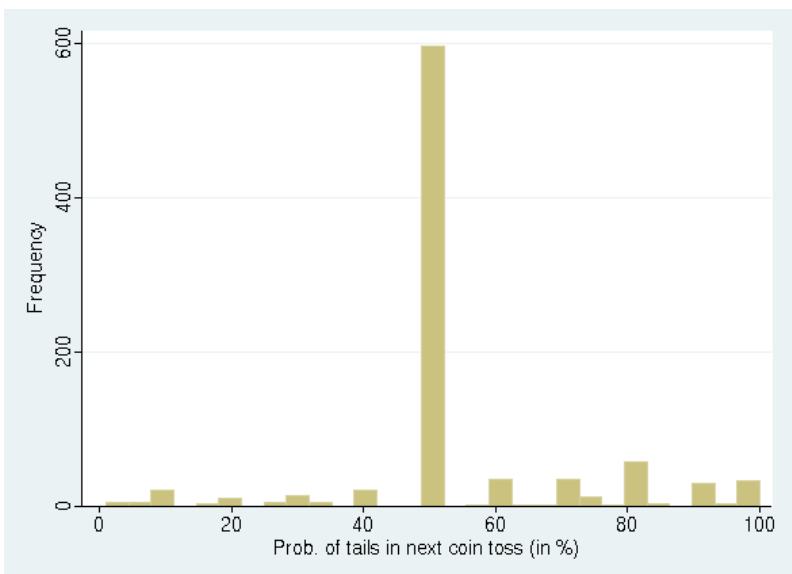

(a) Responses in the Pooled Sample

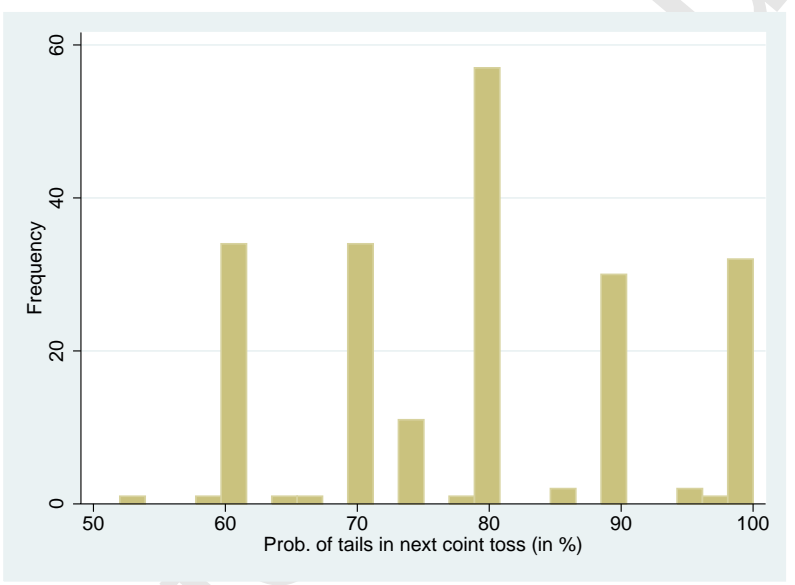

(b) Responses by Respondents with Gambler's Fallacy

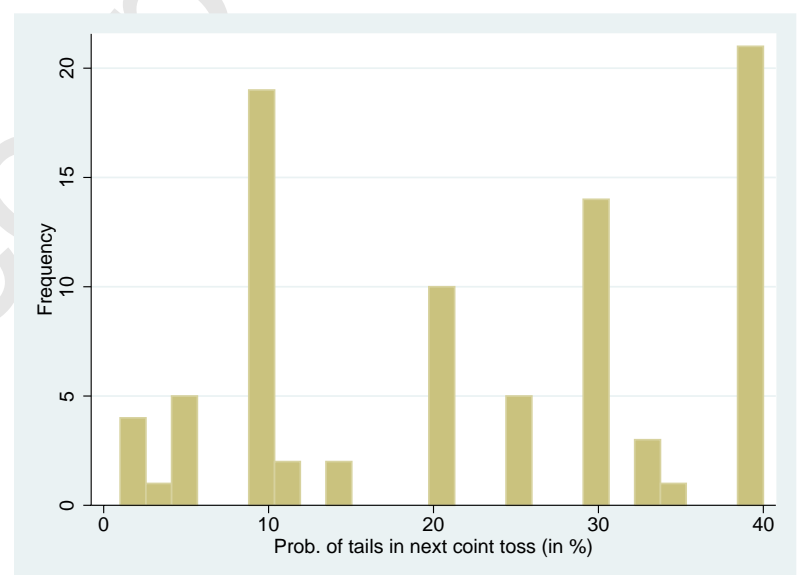

(c) Responses by Respondents with Hot Hand Fallacy

Figure 2: Probability Judgment.

Notes: The normatively correct solution is a pr3Bability of tails of $50 \%$. The 95 observations for the answer "I don't know" are not shown. 
Table 2: Probability Judgment - Descriptive Statistics.

\begin{tabular}{|c|c|c|c|c|c|}
\hline & $\begin{array}{l}\text { Hot } \\
\text { hand }\end{array}$ & $\begin{array}{l}\text { Correct } \\
\text { answer }\end{array}$ & $\begin{array}{c}\text { Gambler's } \\
\text { fallacy }\end{array}$ & $\begin{array}{l}\text { Don't } \\
\text { know }\end{array}$ & $\begin{array}{c}\text { Total } \\
\text { sample }\end{array}$ \\
\hline All & $87(8.8 \%)$ & $596(60.4 \%)$ & $208(21.1 \%)$ & $95(9.6 \%)$ & $986(100 \%)$ \\
\hline Years of schooling $>10$ & $15(4.6 \%)$ & $236(72.6 \%)$ & $60(18.5 \%)$ & $14(4.3 \%)$ & $325(100 \%)$ \\
\hline Years of schooling $\leq 10$ & $72(10.9 \%)$ & $360(54.5 \%)$ & $148(22.4 \%)$ & $81(12.3 \%)$ & $661(100 \%)$ \\
\hline Female & $51(9.6 \%)$ & $296(56.0 \%)$ & $119(22.5 \%)$ & $63(11.9 \%)$ & $529(100 \%)$ \\
\hline Male & $36(7.9 \%)$ & $300(65.6 \%)$ & $89(19.5 \%)$ & $32(7.0 \%)$ & $457(100 \%)$ \\
\hline Age $<50$ & $45(8.1 \%)$ & $349(63.1 \%)$ & $134(24.2 \%)$ & $25(4.5 \%)$ & $553(100 \%)$ \\
\hline Age $\geq 50$ & $42(9.7 \%)$ & $247(57.0 \%)$ & $74(17.1 \%)$ & $70(16.2 \%)$ & $433(100 \%)$ \\
\hline
\end{tabular}

Notes: "Hot hand" refers to answers in the interval $[0 \%, 50 \%)$, "Correct answer" refers to answers equal to $50 \%$, and "Gambler's fallacy" refers to answers in $(50 \%, 100 \%]$. 
Table 3: Probability Judgment - Determinants (I).

\begin{tabular}{|c|c|c|c|c|}
\hline Dependent variable: $=$ & $\begin{array}{c}\text { answer is } 5 \\
\text { (1) }\end{array}$ & $\begin{array}{c}\%,=0 \text { other } \\
(2)\end{array}$ & $\begin{array}{l}\text { ise } \\
(3) \\
\end{array}$ & $(4)$ \\
\hline $\begin{array}{l}\text { Standardized word } \\
\text { fluency score }\end{array}$ & $\begin{array}{c}0.046^{* *} \\
{[0.017]}\end{array}$ & $\begin{array}{c}0.041^{* *} \\
{[0.018]}\end{array}$ & & \\
\hline $\begin{array}{l}\text { Standardized symbol- } \\
\text { digit score }\end{array}$ & & & $\begin{array}{c}0.001 \\
{[0.019]}\end{array}$ & $\begin{array}{l}-0.012 \\
{[0.020]}\end{array}$ \\
\hline Age & $\begin{array}{l}-0.001 \\
{[0.001]}\end{array}$ & $\begin{array}{l}-0.000 \\
{[0.001]}\end{array}$ & $\begin{array}{r}-0.002 * \\
{[0.001]}\end{array}$ & $\begin{array}{l}-0.001 \\
{[0.001]}\end{array}$ \\
\hline 1 if female & $\begin{array}{c}-0.095^{* * *} \\
{[0.033]}\end{array}$ & $\begin{array}{c}-0.097^{* * *} \\
{[0.035]}\end{array}$ & $\begin{array}{c}-0.084^{* * *} \\
{[0.032]}\end{array}$ & $\begin{array}{c}-0.091^{* * *} \\
{[0.033]}\end{array}$ \\
\hline $\begin{array}{l}\text { Years of } \\
\text { schooling }\end{array}$ & & $\begin{array}{c}0.042^{* * *} \\
{[0.010]}\end{array}$ & & $\begin{array}{c}0.046^{* * *} \\
{[0.010]}\end{array}$ \\
\hline $\begin{array}{l}\text { N. Obs. } \\
\text { Prob }>\chi^{2} \\
\text { Pseudo } R^{2}\end{array}$ & $\begin{array}{c}846 \\
0.001 \\
0.017\end{array}$ & $\begin{array}{c}805 \\
0.000 \\
0.034\end{array}$ & $\begin{array}{c}893 \\
0.015 \\
0.009\end{array}$ & $\begin{array}{c}848 \\
0.000 \\
0.028\end{array}$ \\
\hline
\end{tabular}

Notes: Probit estimates, marginal effects evaluated at the mean of observed variables. Standard errors are in brackets. The dependent variable is a dummy indicating whether a respondent gave the correct answer ("50\%"). Observations with the answer "I don't know" are included as incorrect. Cognitive ability measures are standardized. Significance at the 1\%, 5\%, and $10 \%$ level is denoted by $* * *, * *$, and $*$, respectively. 
Table 4: Probability Judgment - Determinants (II).

\begin{tabular}{|c|c|c|c|c|c|c|}
\hline & \multicolumn{6}{|c|}{$\begin{array}{l}\text { (A) Multinomial Logit Estimates } \\
\text { Dependent variable: }=1 \text { if } 50 \%,=2 \text { if } \mathrm{GF},=3 \text { if } \mathrm{HH},=4 \text { if Don't know }\end{array}$} \\
\hline & \multicolumn{3}{|c|}{ (1) } & \multicolumn{3}{|c|}{$(2)$} \\
\hline & $\begin{array}{l}\text { Gambler's } \\
\text { fallacy }\end{array}$ & $\begin{array}{l}\text { Hot } \\
\text { hand }\end{array}$ & $\begin{array}{l}\text { Don't } \\
\text { know }\end{array}$ & $\begin{array}{l}\text { Gambler's } \\
\text { fallacy }\end{array}$ & $\begin{array}{l}\text { Hot } \\
\text { hand }\end{array}$ & $\begin{array}{l}\text { Don't } \\
\text { know }\end{array}$ \\
\hline Standardized word & -0.067 & -0.131 & $-0.614^{* * *}$ & & & \\
\hline fluency score & {$[0.094]$} & {$[0.137]$} & [0.167] & & & \\
\hline $\begin{array}{l}\text { Standardized symbol- } \\
\text { digit score }\end{array}$ & & & & $\begin{array}{c}0.152 \\
{[0.106]}\end{array}$ & $\begin{array}{l}-0.142 \\
{[0.143]}\end{array}$ & $\begin{array}{l}-0.041 \\
{[0.179]}\end{array}$ \\
\hline Age & $\begin{array}{c}-0.012^{* *} \\
{[0.006]}\end{array}$ & $\begin{array}{l}-0.004 \\
0.007]\end{array}$ & $\begin{array}{c}0.035^{* * *} \\
{[0.008]}\end{array}$ & -0.004 & $\begin{array}{l}-0.002 \\
{[0.008]}\end{array}$ & $\begin{array}{l}0.036^{* * *} \\
{[0.010]}\end{array}$ \\
\hline 1 if female & $\begin{array}{l}0.354^{*} \\
{[0.182]}\end{array}$ & $\begin{array}{c}0.35 \\
{[0.257]}\end{array}$ & $\begin{array}{l}0.662^{* *} \\
{[0.281]}\end{array}$ & $\begin{array}{l}0.297^{*} \\
{[0.174]}\end{array}$ & $\begin{array}{c}0.395 \\
{[0.246}\end{array}$ & $\begin{array}{c}0.753^{* *} \\
{[0.303]}\end{array}$ \\
\hline $\begin{array}{l}\text { Years of } \\
\text { schooling }\end{array}$ & $\begin{array}{c}-0.122^{* *} \\
{[0.053]}\end{array}$ & $\begin{array}{c}-0.293^{* * *} * \\
{[0.080]}\end{array}$ & $\begin{array}{c}-0.225^{* * *} * \\
{[0.087]}\end{array}$ & $\begin{array}{c}-0.144^{* * *} \\
{[0.051]}\end{array}$ & $\begin{array}{c}-0.294^{* * *} * \\
{[0.075]}\end{array}$ & $\begin{array}{c}-0.271 * * * \\
{[0.095]}\end{array}$ \\
\hline Constant & $\begin{array}{c}0.55 \\
{[0.651]}\end{array}$ & $\begin{array}{c}1.062 \\
{[0.922]}\end{array}$ & $\begin{array}{c}-2.145^{* *} \\
{[1.071]}\end{array}$ & $\begin{array}{c}0.448 \\
{[0.624]}\end{array}$ & $\begin{array}{c}0.986 \\
{[0.878]}\end{array}$ & $\begin{array}{l}-1.826 \\
{[1.174]}\end{array}$ \\
\hline $\begin{array}{l}\text { N. Obs. } \\
\text { Log likelihood } \\
\text { Prob }>\chi^{2}\end{array}$ & & $\begin{array}{c}805 \\
-802.33 \\
0.000\end{array}$ & & & $\begin{array}{c}848 \\
-839.68 \\
0.000\end{array}$ & \\
\hline
\end{tabular}

(B) Multinomial Probit Estimates

Dependent variable: $=1$ if $50 \%,=2$ if $\mathrm{GF},=3$ if $\mathrm{HH},=4$ if Don't know

(1)

Notes: Panel (A) contains multinomial logit estimates, Panel (B) contains multinomial probit estimates, standard errors in brackets. The dependent variable equals 1 if correct answer ("50\%"), 2 if gambler's fallacy $(>50 \%), 3$ if hot hand fallacy $(<50 \%)$, and 4 if "don't know". The reference category is the correct answer. Cognitive ability measures are standardized to have mean 0 and standard deviation 1 . Significance at the $1 \%, 5 \%$, and $10 \%$ level is denoted by $* * *$, ** and *, respectively. 


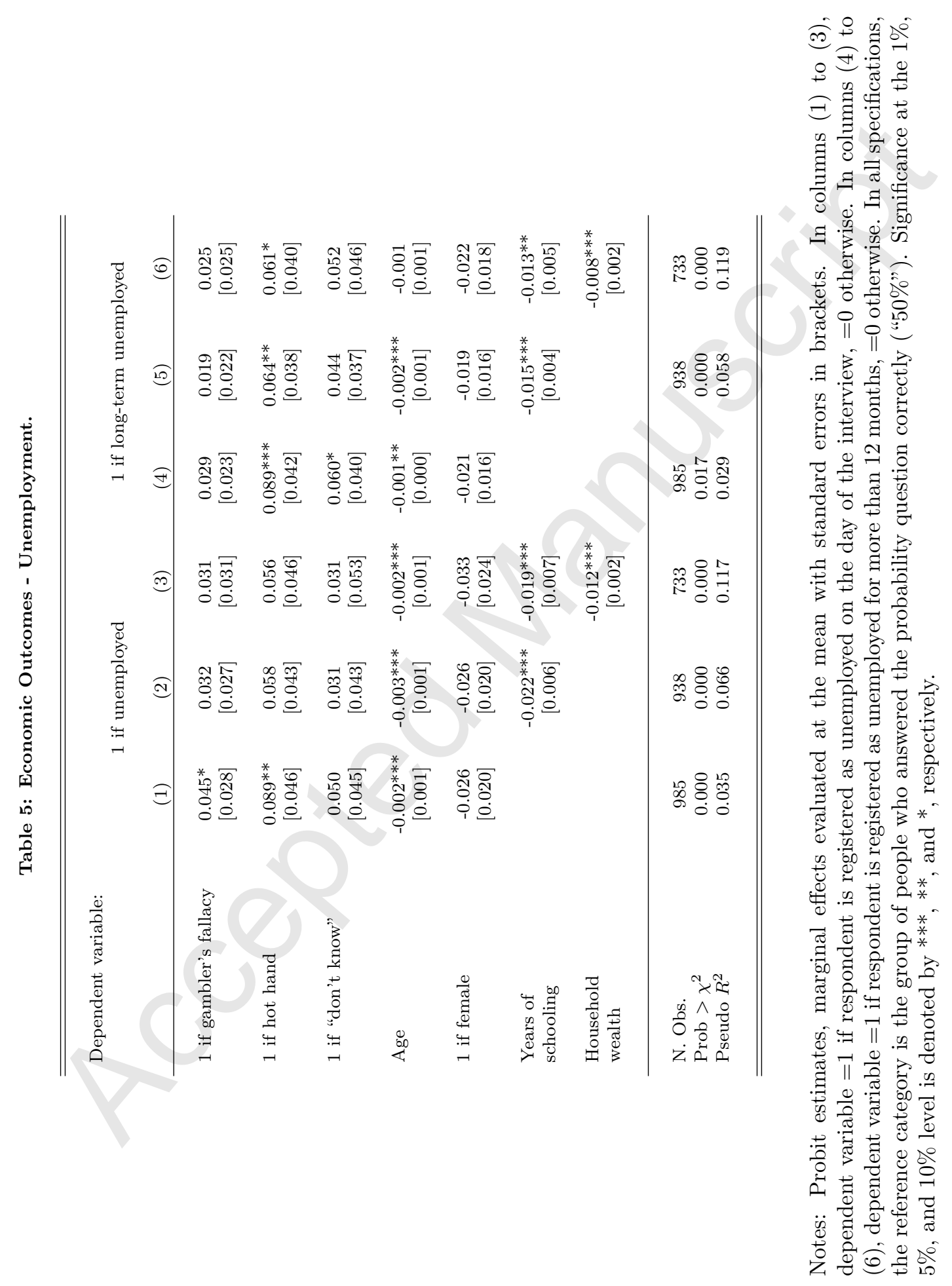




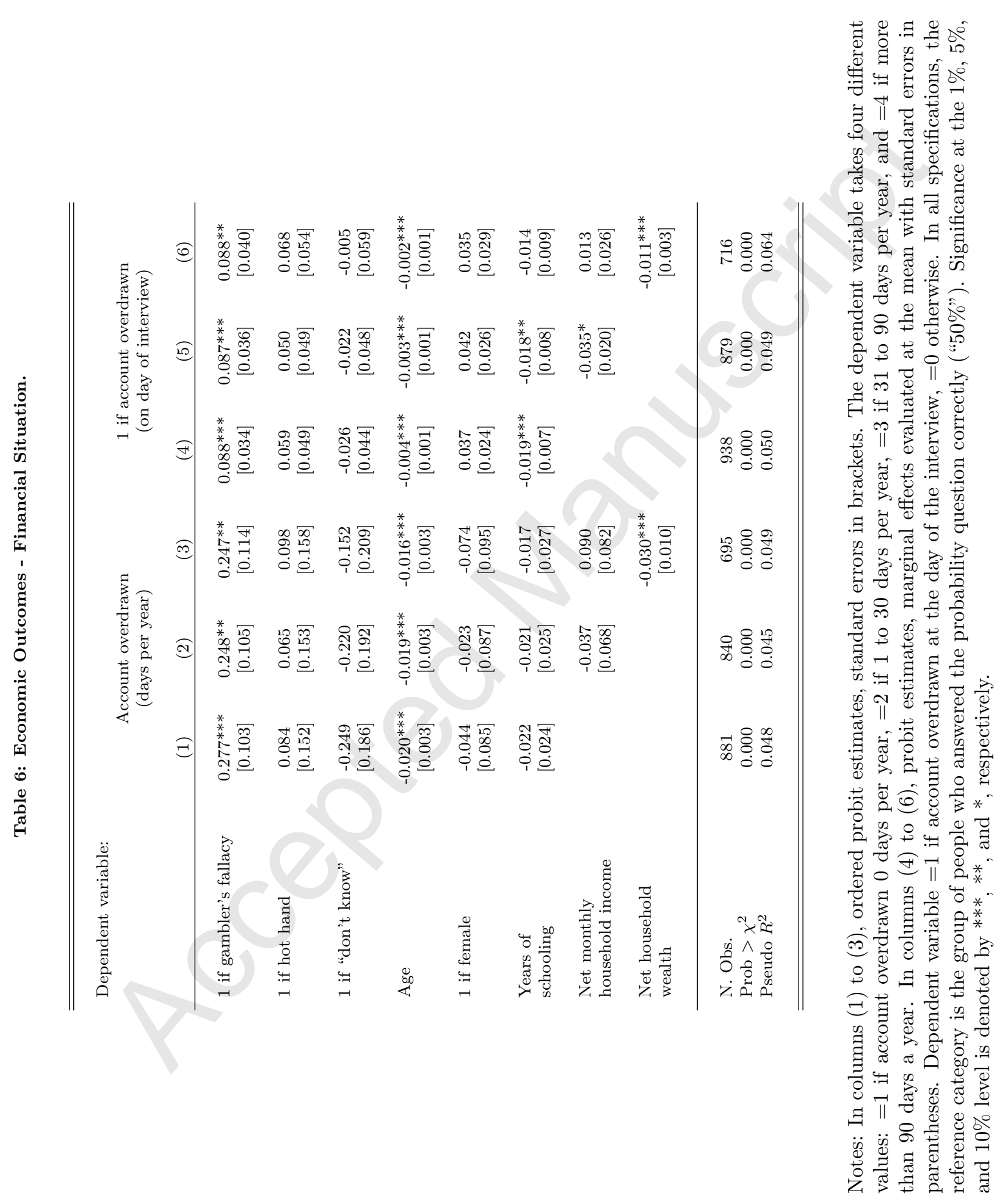

